\title{
Is the syndrome of pathological laughing and crying a manifestation of pseudobulbar palsy?
}

\author{
WILSON T ASFORA, ANTONIO A F DeSALlES, MASAMITSU ABE, \\ RAYMOND N KJELLBERG
}

From the Department of Neurological Surgery, Massachusetts General Hospital, Harvard University, Boston, $M A, U S A$

SUMMARY A case of angiographically occult brainstem vascular malformation presenting solely with pathological laughing and crying is reported. Although this emotional syndrome has been seen in association with several different pathological entities, review of the literature failed to identify its occurrence as the only clinical expression of angiographically occult brainstem vascular malformation, or as a solitary symptom in any disease. Our data suggest that pathological laughing and crying can occur without any other manifestation of pseudobulbar palsy. An attempt is made to correlate this patient's clinical and radiological findings. This case was treated by stereotactic Bragg-peak proton beam therapy.

Spasmodic laughing and crying is always indicative of underlying brain pathology. ${ }^{1}$ It has been reported to occur in several conditions. ${ }^{2-26}$ Our case appears to be unique in that it consists of an angiographically occult brainstem vascular malformation, a relatively rare entity, that presented itself with the insidious onset of inappropriate emotional $e_{x}$ pression which progressed to the full syndrome of "pathological laughing and crying" without any abnormality of voluntary or automatic facial movements.

\section{Case report}

A 39 year old, right handed, Caucasian male had enjoyed excellent health until June 1986, at which time he started to experience occasional episodes of inappropriate and involuntary laughing and crying, or a mixture of both, which could be elicited by nonspecific and varied stimuli. Over the ensuing weeks these episodes became more frequent and annoying to the patient. There was a predominance of laughing over crying, and often crying would follow the laughter. During these episodes, the patient related feeling no emotion of mirth or sadness. He denied headaches, nausea, vomiting, tinnitus, visual disturbances, any motor or sensory symptoms;

Address for reprint requests: Wilson T Asfora, MD, Section of Neurosurgery, University of Manitoba, 61 Emily Street, Winnipeg, Manitoba, Canada R3E 1 Y9.

Received 15 March 1988 and in revised form 3 November 1988. Accepted 8 November 1988 however, early in the course of the disease, the patient reportedly had an obscure viral illness with accompanying lethargy, mild slurring of speech and swallowing difficulties. The patient's past history was noncontributory. He was on no medication. His first physical examination in August 1986 revealed a healthy male who appeared depressed. There was marked lability of emotional expression. The general physical examination, as well as neurological examination, were otherwise unremarkable. His speech was normal and there was no swallowing difficulty, facial asymmetry or weakness of face on smile or voluntary grimace. The jaw and gag reflexes were normal. No sensory changes in the face were noted. A brain tumour had been suspected and the patient initially underwent CT without contrast which showed a region of increased density in the midpons. It enhanced slightly after the injection of contrast. Subsequent MRI confirmed a subacute haemorrhage in the anterior upper brainstem with minimal mass-effect (fig a). There was a strong suggestion of a number of small abnormal vessels in the region. These findings were felt to be consistent with a small vascular malformation which had bled. Brainstem auditory and somatosensory evoked potential studies were carried out and reported to be normal. A three-vessel angiogram was done which failed to reveal a vascular malformation, but showed slight displacement of the basilar and right posterior-inferior cerebellar artery, consistent with intrinsic compression.

Over the summer, the patient's symptoms plateaued and in September they began to abate. He was referred to a neurosurgeon who decided that the lesion was inoperable and stereotactic radiosurgery was suggested to prevent rebleed. The patient was admitted in December 1986 for treatment of 

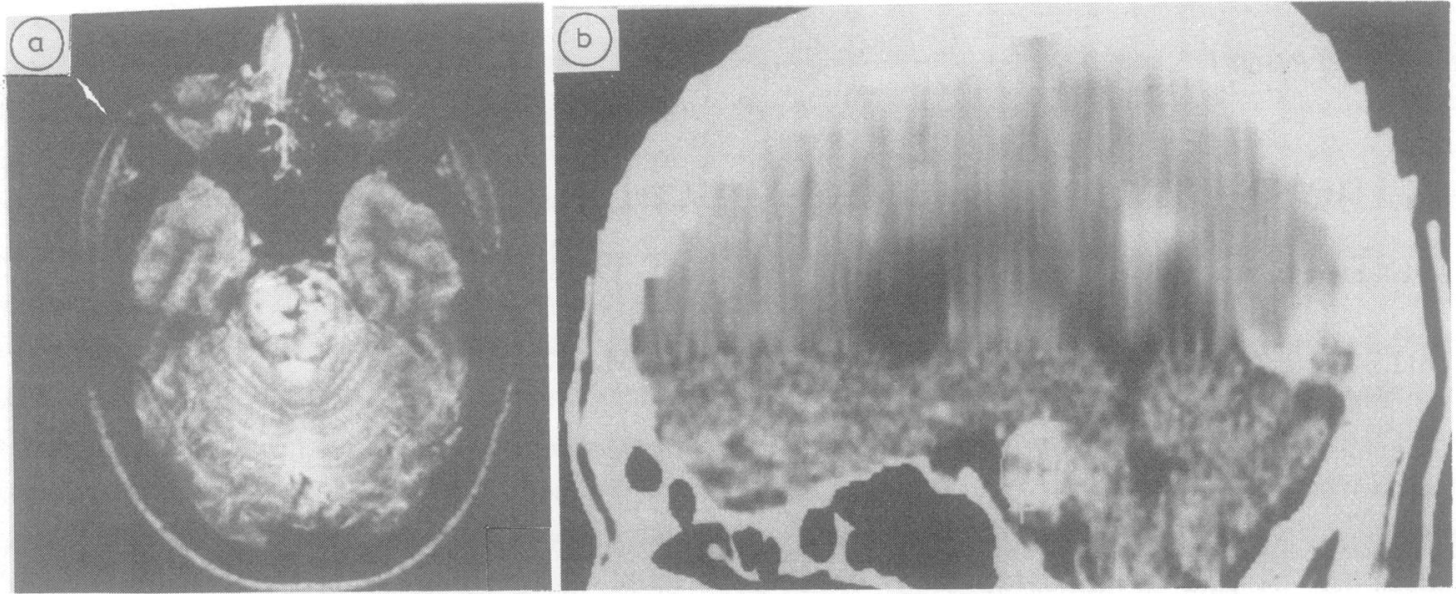

Fig (a) MRI axial T2-weighted image $(T R=2550 \mathrm{~ms}, T E=100 \mathrm{~ms}$ ) discloses a hyperintense region (free methaemoglobin) situated in basis pontis consistent with subacute haemorrhage. Linear areas of medium and low signal intensity around and to the left of midline most likely represent abnormal vessels. (b) CT sagittal reconstruction shows an area of enhancement in upper basis pontis extending slightly into the midbrain. The lesion is outlined and the greatest diameter on this plane measured $1.89 \mathrm{~cm}$. The AP diameter measured $1.45 \mathrm{~cm}$. (These measurements were used for the determination of the target volume/beam size in preparation for Bragg peak proton beam therapy.)

his lesion. At that point, he still had residual pathological laughing, followed occasionally by crying, which, interestingly, was now only elicited by a stimulus which tended to provoke anger. Neurological examination was again otherwise normal. A CT scan with contrast revealed an enhancing lesion located in the basis pontis (fig b). Stereotactic Bragg peak proton beam therapy was performed uneventfully via two portals with a $22 \times 16 \mathrm{~mm}$ beam. Target determination was based on CT scan and MRI data ${ }^{27}$ and total dose delivered was 1400 rads. ${ }^{29}$ The patient continues to be followed and his symptoms, now 22 months after treatment, have completely subsided.

\section{Discussion}

The facial and other brainstem nuclei appear to be under the influence of separate supranuclear pathways for voluntary, emotional and automatic facial movements. ${ }^{30}{ }^{31}$ Our data suggest that the disinhibition of the emotional apparatus is due to a lesion that does not clinically derange corticobulbar tracts. There is no doubt that the majority of patients with pathological laughter and crying have pseudobulbar palsy due to bilateral corticobulbar lesions and often a bipyrimidal involvement of arms and legs. The crucial question is whether this emotional disorder can occur only if the corticobulbar lesion is present and has disinhibited the facio-bulbar respiratory mechanism. Poeck ${ }^{8}$ has examined this question and was unable to substantiate this mechanism from his own cases and those extracted from the medical literature. Wilson ${ }^{11}$ speculated about the existence of an upper pontine supranuclear facio-respiratory centre integrating both facial and respiratory mechanisms for emotional expression and controlled by corticofugal paths that are independent of the voluntary corticobulbar tracts. These nonpyramidal paths are said to be disinhibited by lesions of the corticobulbar tracts. The haemorrhage in ouro patient appeared to interrupt some inhibiting influence exerted by the corticobulbar tracts over this mechanism without disruption of its direct connection? with the pontine and medullary motor nuclei, thus resulting in no disturbances of volitional facial, lingual, pharyngeal or laryngeal movements. Our patient's lesion was situated mostly in the midline of the upper basis pontis, which conceivably, could interrupt afferent connections from the basis pontis to a midline upper pontine tegmental centre for the control of laughing and crying.

Another point high-lighted by this case is the striking incongruity between the relatively large size of the brainstem haemorrhage and the presence of only an isolated symptom. Even the brainstem evoked potentials were normal. Thus, we are not able to determine with accuracy the precise lesion site which produced this patient's emotional syndrome.

This case, and others in our series, suggest that the bleeding characteristics of angiographically occult brainstem vascular malformations differ from those of larger vascular malformations or hypertensive haemorrhages. We believe the difference is related to the small size of the component vessels and the slow flow of blood through them. It is possible that many of these haemorrhages are of venous origin. These factors would account for the comparatively smaller size, 
less forceful and less destructive haemorrhages, which may dissect and infiltrate the brain tissue, often inducing reversible loss of function.

In conclusion, we have described the rare association of an angiographically occult brainstem vascular malformation and pathological laughing and crying as the sole presenting symptom. The neuroanatomic basis of emotional display is still not well understood. This case suggests that the facio-respiratory mechanism involved in involuntary emotional expression may be selectively disinhibited of higher control, without detectable abnormality of voluntary movements or reflexes, producing inappropriate uncontrollable laughing and crying.

The authors are grateful to Dr Raymond D Adams for his invaluable advice during the preparation of this manuscript, as well as $\mathbf{R} \mathbf{M}$ Moffet for secretarial assistance.

\section{References}

1 Adams RD, Victor $M$. The limbic lobes and the neurology of emotions. In: Adams RD, Victor M, eds. Principles of Neurology, 3rd ed: St Louis: McGraw-Hill, Inc., 1985, Part II, 381-92.

2 Brain WR. Multiple sclerosis. In: Brain WR, Walton JN, eds. Brain's Diseases of the Nervous System, ed 8, London: Oxford University Press, 1977:544-63.

3 Charcot JM. Lectures on the diseases of the nervous system. Sigerson G (trans). London: New Sydenham Society, 1881: 182-201.

4 Davison C, Kelman H. Pathologic laughing and crying. Arch Neurol Psychiat 1939;42:595-632.

5 La Loizou GC. Acute cerebral demyelinaton: Clinical and pathological correlation with computed tomography. J Neurol Neurosurg Psychiatry 1982;45:725-8.

6 Brain WR. Motor neuron disease. In: Brain WR, Walton JN, eds. Brain's Diseases of the Nervous System, ed 8. London: Oxford University Press, 1977:682-94.

7 Lieberman A, Benson DF. Control of emotional expression in pseudobulbar palsy. Arch Neurol 1977;34:717-9.

8 Poeck K. Pathophysiology of emotional disorders associated with brain damage. Handbook of Neurology 1969;3:343-67.
9 Ironside R. Disorders of laughter due to brain lesions. Brain 1956;79:589-609.

10 Swash M. Released involuntary laughter after temporal lobe infarction. J Neurol Neurosurg Psychiatry 1972;35:108-13.

11 Wilson SAK. Some problems in neurology. No II-Pathological laughing and crying. J Neurol Psychopathol 1924;4:299-333.

12 Achari AN, Colover J. Posterior fossa tumors with pathological laughter. JAMA 1976;235:1469-71.

13 Brain WR. Intracranial tumor. In: Brain WR, Walton JN, eds. Brain's Diseases of the Nervous System, ed 8. London: Oxford University Press, 1977;230-96.

14 Chen R, Forster FM. Cursive and gelastic epilepsy. Neurology 1973;23:1019-29.

15 Daly DD. Gelastic epilepsy. Neurology 1957;7:189-92.

16 Druckman R, Chao D. Laughter in epilepsy. Neurology 1957; 7:26-36.

17 Offen ML. Dacrystic epilepsy. J Neurol Neurosurg Psychiatry 1976;36:829-34.

18 Weill AA, Noskina DN. Electroencephalographic correlation of laughing fits. Am J Med Sci 1958;235:301-8.

19 Caine ED, Hunt RD, Weingartner H, et al. Huntington's dementia. Arch Gen Psychiatry 1978;35:377-84.

20 Poeck K, Pilleri G. Pathologisches lachen uno weinen. Schweizer Archiv Neurol Psychiatr 1963;92:323-70.

21 Scheinberg IH, Sternlieb I, Richman J. Psychiatric manifestations in patients with Wilson's disease. Birth Defects 1968;4:85-7.

22 Beal MF. Primary lateral sclerosis. Arch Neurol 1981;38:630-3.

23 Langworthy OR, Hesser FH. Syndrome of pseudobulbar palsy. An anatomic and physiologic analysis. Arch Intern Med 1940; 65:106-21.

24 Kramer HC. Laughing spells in patients after lobotomy. $J$ Nerv Ment Dis 1954;119:517-22.

25 Judkins KC. Postrecovery of emotional lability following althesin (letter). Anesthesia 1978;33:72.

26 Britt RH, Connor WS, Enzmann D. Occult arteriovenous malformation of the brainstem simulating multiple sclerosis. Neurology 1981;31:901-3.

27 DeSalles AAF, Asfora WT, Abe M, et al. Transposition of target information from NMR and CT scan images to conventional skull x-ray stereotactic space. Appl Neurophysiol 1987;50:23-32.

$28 \mathrm{Kjellberg} \mathrm{RN.} \mathrm{Stereotactic} \mathrm{Bragg} \mathrm{peak} \mathrm{proton} \mathrm{radiosurgery}$ method. In: Szikla G, ed. Stereotactic Cerebral Irradiation INSERM Symposium No 12. Amsterdam: Elsevier/NorthHolland Biomedical Press, 1979:93-100.

$29 \mathrm{Kjellberg} \mathbf{R N}$. Isoeffective dose parameters for brain necrosis, in relation to proton radiosurgical dosimetry. In: Szikla G, ed. Stereotactic Cerebral Irradiation INSERM Symposium No 12. Amsterdam: Elsevier/North-Holland Biomedical Press, 1979: 157-66.

30 Kahn EA. On facial expression. Clin Neurosurg 1964;12:9-22.

31 Carpenter MB. The Hypothalamus. In: Carpenter MB. Core Text of Neuroanatomy. Williams and Wilkins, 1972:170-8. 